\title{
Industry-directed training and research programmes: The BMI experience
}

AUTHORS:

Pieter J. de Jongh ${ }^{1}$

Cornelius M. Erasmus 2,3

\author{
AFFILIATIONS: \\ ${ }^{1}$ Centre for Business \\ Mathematics and Informatics, \\ North-West University, \\ Potchefstroom, South Africa \\ ${ }^{2}$ Head of University Governance \\ and Research in the Public \\ Sector, Absa, Johannesburg, \\ South Africa \\ ${ }^{3}$ Extraordinary Professor, Centre \\ for Business Mathematics \\ and Informatics, North-West \\ University, Potchefstroom, \\ South Africa
}

\section{CORRESPONDENCE TO:}

Pieter de Jongh

EMAIL:

Riaan.DeJongh@nwu.ac.za

\section{POSTAL ADDRESS:}

Centre for Business Mathematics and Informatics, NorthWest University, Private Bag X6001, Potchefstroom 2520, South Africa

\section{DATES:}

Received: 21 Dec. 2013

Revised: 04 Apr. 2014

Accepted: 04 Apr. 2014

\section{KEYWORDS:}

mathematical and statistical science; quantitative risk management; business mathematics and informatics; design and implementation

\section{HOW TO CITE:}

De Jongh PJ, Erasmus CM. Industry-directed training and research programmes: The BMI experience. S Afr J Sci. 2014;110(11/12), Art. \#2013-0392, 8 pages. http://dx.doi.org/10.1590/ sajs.2014/20130392
Universities are academic institutions with the primary objectives of teaching students a particular academic discipline and for conducting research related to that discipline. Traditionally, very little collaboration existed between universities and industry with respect to training and research in the mathematical sciences. Because of funding pressure, more and more universities are forced to find external sources of income. In this paper, we discuss a framework for designing and implementing career-oriented training programmes and industry-directed research programmes with a statistical science core. This framework was used as the basis for designing and implementing a highly successful training and research programme at North-West University's Centre for Business Mathematics and Informatics ${ }^{\circledR}$ (Centre for BMI), with the active support of industry partners Absa and SAS Institute. We believe that the lessons learnt from its implementation could form valuable guidelines for other, similar initiatives.

\section{Introduction}

We propose a management framework for training students for professional careers in business and industry as well as for conducting industry-directed research in the mathematical sciences, with a specific focus on a statistical science core. The framework has been designed and implemented by us at North-West University's (NWU) Centre for Business Mathematics and Informatics ${ }^{\circledR}$ (Centre for BMI) where the training and research programme is referred to as the BMI programme. Note that although statistical sciences constitute the core of our programme, several mathematical sciences are included in the programme, namely the disciplines of pure mathematics, applied mathematics and operational research. In addition, information technology is incorporated because it provides the environment for the effective implementation of the framework.

The framework will be explained in generic terms and the BMI programme will be used to illustrate the implementation thereof. The BMI programme was launched in 1998 with an intake of 11 first-year students and has grown to nearly 400 registered students in 2013. To date, 297 BMI MSc students have been delivered of which about 15 have chosen to follow academic rather than professional careers. Students who complete the honours and master's programmes find work easily and are employed before or soon after completing their studies. Absa has supported the programme since its inception by donating funds for capacity building and student bursaries whilst the SAS Institute has supported the programme since 2001 and recently donated USD300 000 to expand the programme to include an MSc BMI course in Business Analytics/Data Science. The current 5-year contract with Absa (the fourth since inception) commenced in 2011 and involves an annual donation of approximately ZAR3 million to ensure the sustainability of the Centre, ZAR4 million towards BMI student bursaries and ZAR1.5 million towards conducting applied risk research projects for Absa. Over the years a host of industry-directed research projects have been delivered by the MSc students as well as a number of technical research reports by BMI staff under the Absa applied research programme. The popularity of the graduates amongst companies and recruiting agencies as well as the industry involvement in the training and research programmes are testimony to the success of this flagship programme of the NWU. Some further achievements of the Centre for BMI are provided in the Online Supplementary Material.

\section{Background}

The Centre for BMI was established in 1998 as a joint venture between the erstwhile Potchefstroom University for CHE and Absa Bank. The main reason for the establishment of the Centre for BMl by the university management was twofold: a need to increase the number and quality of postgraduate students in mathematical sciences, and the success of the BMI programme at the Vrije Universiteit van Amsterdam (VU). The Dutch programme carried the same name (BMI, or in Dutch, BWI - Bedrijfswiskunde en Informatica) and had been developed in close cooperation with the RABO bank in the Netherlands. Based on this concept, the university convinced Absa to enter into a similar relationship. Boersma et al. ${ }^{1}$ provide greater detail regarding the establishment and initial implementation of the Centre for BMI from a university management and transformation perspective. In this article, we focus on the implementation of the framework at an operational level.

We were appointed during 1997 with the mandate to design and implement a training programme along the lines of the existing BMI programme at the VU. The VU BMI programme was essentially an operational research programme, which consisted of subjects such as mathematics, operational research, statistics and computer programming, with the distinguishing addition that students were required to do a 'stage' or MSc project on-site at a company in industry. Our first attempt at designing a curriculum, largely based on the VU BMI curriculum, was rejected by Absa at the end of 1997 because it did not meet their requirements. This led to a fundamental reconsideration of the curriculum design, specifically to add a focus on risk management in banking. The NWU $\mathrm{BMI}$ curriculum then developed independently and separately from that of the VU (although it did include the 'stage' concept), and changes were effected annually in order to continuously improve it in line with industry requirements. It is interesting to note that the $\mathrm{VU}$ recently changed the name of their BMI programme to Business Analytics, suggesting that the VU BMI brand name did not receive the same widespread industry recognition in the Netherlands as its offspring did in South Africa. 


\section{Overview of relevant statistical literature (1998-2000)}

Our approach was shaped mostly by relevant statistical literature in circulation between 1997 and 2000. At the turn of the century it was clear that the subject of statistics was becoming extremely popular in many application areas such as finance, health care and pharmaceuticals, manufacturing and quality-management marketing and service improvement, environmental sciences, and risk management. In finance, the first version of the Basel Accord in 1988 prescribed the use of statistically based risk measures and procedures as regulatory requirements to guard against bank failure, which has led to a significant rise in the demand for risk-management expertise ever since. Major developments in communications and computer technologies such as e-commerce and e-intelligence began to have a considerable impact on the way of doing business and data were collected and stored in massive amounts. Hand ${ }^{2}$ warned the statistical community of several new challenges inherent to the statistical analysis of massive data sets. Companies are interested in utilising these huge data sets (presently referred to as big data) to improve, amongst others, their marketing campaigns, customer relationships, pricing strategies and risk management. According to Lambert ${ }^{3}$ and Nelder ${ }^{4}$, it was clear that the definition of statistics as a subject was widening, that many new application areas were increasingly making use of statistics, and that many open problems and challenges remain in evidence. Lawless ${ }^{5}$ made an important observation that the definition of statistics is changing from scientific enquiry to one of problem solving, while Hahn and Hoerl ${ }^{6}$ stated that there was a growing awareness of the value of and need for statistics in US business and industry.

The growing need for statistics resulted in a corresponding demand for appropriately trained people in the discipline. However, many authors (for example see Billard ${ }^{7}$ ) expressed concerns, because the typical academic training received by students did not prepare them adequately for business and industry. Several author ${ }^{5,6,8-10}$ felt that statisticians were not highly regarded in business and industry because they generally did not possess the necessary skills to function effectively in that environment and also did not have enough knowledge of the area in which they applied their skills. These and other authors $5,6,8-12$ reported that students trained in the mathematical sciences were lacking skills such as subject matter expertise, creative problem solving, project planning and management, problem structuring and formulation, meeting management, group and team dynamics, as well as technical writing, presentation and persuasion skills.

During the course of our interaction with academia, we were often struck by the lack of understanding amongst some academics regarding the needs of business and industry. This perceived lack of understanding may be partly because of unwillingness to show interest in the problems faced by business and industry. Gnanadesikan and Kettenring ${ }^{12}$ made the same observation: 'Instructors need to have industrial experience. Would a medical student want to learn surgery from professors who have never done it?' Further contributing factors to the tendency of academics to shy away from the problems faced by industry are the performance appraisal system and promotion criteria employed by many universities. This system exerts a great deal of pressure on researchers to produce publications and perform research purely for the sake of research and does not necessarily reward research aimed at improving business competitiveness. Therefore one of the greatest challenges faced by a successful industry-university alliance is the requirement to break through these barriers which may exist between academia and industry.

Iman $^{13}$ expressed a concern about the demise of statistics departments and claimed that most academic departments in the mathematical sciences had difficulty attracting young people to pursue an academic career, mainly because of poor salaries and a lack of funding. (Today the South African Statistical Association (SASA) is involved with a strategic initiative that is aimed at resolving a national crisis in academic statistics. At many universities, the statistics departments have difficulty offering postgraduate programmes in statistics and internationally acclaimed researchers in the field can be counted on one hand.) Government funding is limited and universities are forced to generate nongovernmental sources of income to balance their books. External funds are difficult to acquire and industry increasingly expects return on their investments in higher education. Furthermore, universities are facing increased competition from foreign universities and other institutions as a result of globalisation. It is therefore of the utmost importance that universities should design programmes that are globally competitive and have the potential to earn income from non-governmental sources. This principle guides the design of our industry-directed training and research programmes.

It is interesting to note that all the views expressed a decade ago are still true today, as demonstrated by the presidential addresses of the most recent presidents of the American Statistical Association, namely Geller ${ }^{14}$ and Rodriguez ${ }^{15}$. The subject of statistics is more popular than ever, and although some progress has been made, the issue of industry-relevant training of statisticians has not been resolved and statistics departments still struggle to appoint appropriately trained staff.

We used the views expressed in this section as drivers for the design of our framework and for monitoring the successful implementation thereof.

\section{Designing a framework for industry-directed training and research}

In order to design a generic industry-directed training and research framework, we had to consider the following key aspects:

- the application and focus areas for training and research,

- the design concept for implementing the career-oriented training and industry-directed research programmes, and

- management and governance structures and processes required.

\section{The application and focus area}

Consider the so-called 'BMI Triangle' shown on the left side of Figure 1. This triangle formed the basis of the VU BMI programme, which we altered slightly by incorporating a specific focus, as depicted in Figure 1b. (When the Centre for BMI was established, we chose business economics as the application area and quantitative risk management as our focus area.) The basis of the triangle is made up of the mathematical sciences at one corner and computer/information science at the other. As stated by Kettenring ${ }^{9}$, the mathematical sciences and computer science should form the basis of any career that is built around a statistical science core. The above-mentioned sciences should then be applied in a preselected application area, such as health sciences or economic sciences. It is interesting to note that this triangle allows you to plot many of the 'non-pure' disciplines, such as econometrics, on one side of the triangle, moving to the inside of the triangle allows you to depict application or focus areas that require an interdisciplinary problem-solving approach.

As stated previously, many application areas are possible, and the particular choice depends on the following factors:

- The likelihood of obtaining industry partners or sponsors requiring graduates who understand the particular industry, are highly skilled in the mathematical sciences and computer science, and have the necessary problem-solving and business skills.

- The professional career opportunities in the particular industry.

- The support that the programme will receive from the university, especially senior management.

- The likelihood of obtaining lecturers with the necessary technical qualifications and business experience.

- The experience, expertise and interests of the employed academics at the particular university.

- $\quad$ The relationship that exists between the departments involved (i.e. statistics, computer science and the application area), in particular how far apart they are in the university organisational structure. 
- The existence of similar programmes at the university in other departments that could act either as a barrier or as support.

\section{- Proximity and standing of the university with the particular industry.}

It could well happen that the application area is too broad, which then requires defining a focus area within the broader spectrum to ensure the required focus for a successful implementation. This scenario is depicted in the 'focused BMI Triangle' in which we decided to place our focus - quantitative risk management - in the middle of the triangle. The important concept to note is that the three corners of the triangle provide the basis upon which one or more such focus areas could be built.

The importance of forming constructive partnerships within the university cannot be overstated. In this regard one should involve the mathematics, applied mathematics, statistics and computer science departments when developing the career-oriented training programmes. Of course, given the application area, another department may have to be involved as well, for example if the application area is business economics with risk management in banking as the focus area, the Department of Economics/Accounting should play an important role. One of the most important design considerations is to formulate a vision for the chosen application/focus area upfront that will serve to grow into a Centre of Excellence or something similar. This vision then has to be unpacked into a clear mission statement, which will drive its implementation.

\section{The design concept for implementation of the framework}

Working forward from the basis established by the triangle concept, the next step is to define an implementation framework or operating model that can be used to operationalise the concept. To illustrate our implementation framework we use Figure 2, which is a Venn diagram consisting of three overlapping circles depicting a set of 'Training', 'Research' and 'Industry' activities that will be described in more detail below.

At first, let us consider the set of activities indicated as 'Basic Training' in Figure 2. After deciding on the particular application area (including a focus area if applicable), a decision has to be made regarding the careers for which we aim to prepare the students. When determining the content and delivery method of the training, we need to consider the needs of industry in the particular focus area. Based on the type of problems experienced by the particular industry, the characteristics (skills, subject matter knowledge, etc.) required by these careers can be determined. These characteristics then provide the specific focus for the career-oriented training programmes and give the necessary input to design the curricula, as well as the training methods to develop the required skills. This design should be done in close collaboration with one or more industry partners, but with the understanding that one is embarking on a process which will require continuous improvement as the needs of industry and your understanding thereof evolve.

Meetings and work sessions may be held initially to determine particular requirements in the form of the skills and knowledge that the students should possess in order to function effectively in the chosen focus area. The curricula of other universities and international training programmes in the particular area may also be referenced when designing your own curriculum. In order to incorporate all the requirements, the careeroriented training programme, in our opinion, should span at least five academic years, as is the case with most professional training programmes. For the duration of the undergraduate studies (the first three years), focus should still be placed on the important theoretical concepts and principles of the mathematical sciences, but courses in the selected application area should be gradually incorporated. These activities are carried out in the area designated as 'Basic Training' in Figure 2.

Next, consider the set of activities indicated as 'Integration Training' where the 'Training' and 'Industry' diagrams overlap. In the graduate programmes (BSc Hons and MSc), specific courses should be included to train students in the non-technical skills that were mentioned earlier and to integrate their knowledge to solve real-world problems. Most of the training should preferably be of an 'on-the-job' nature and occur concurrently with the students working on a particular project. During the fourth and fifth years, the programme should focus on the integration of subjects and the students should solve various practical problems using the knowledge and skills they have acquired. The heart of the programme is the set of activities labelled 'Student Industry Projects' where all three circles overlap in Figure 2. These activities represent the 'stage' idea, which we adopted from the VU programme. Using our industry experience, $\mathrm{we}^{16}$ developed a detailed procedure for conducting and executing the student projects in industry. The basic idea is that all MSc students in the programme are required to complete an individual, substantial (6-month) industry-directed research project under the mentorship of an assigned client project officer (who is employed by industry and assumes responsibility for the business success of the project) and an academic supervisor (who is employed by the university and is responsible for the academic/technical quality of the project). (Note that, in the university structure, the industry-directed research project is classified as a mini-dissertation.) The particular project should be carefully chosen in collaboration with the client so as to solve a problem faced by the client, whilst simultaneously encompassing the requisite academic content. The students, who are able to bid for

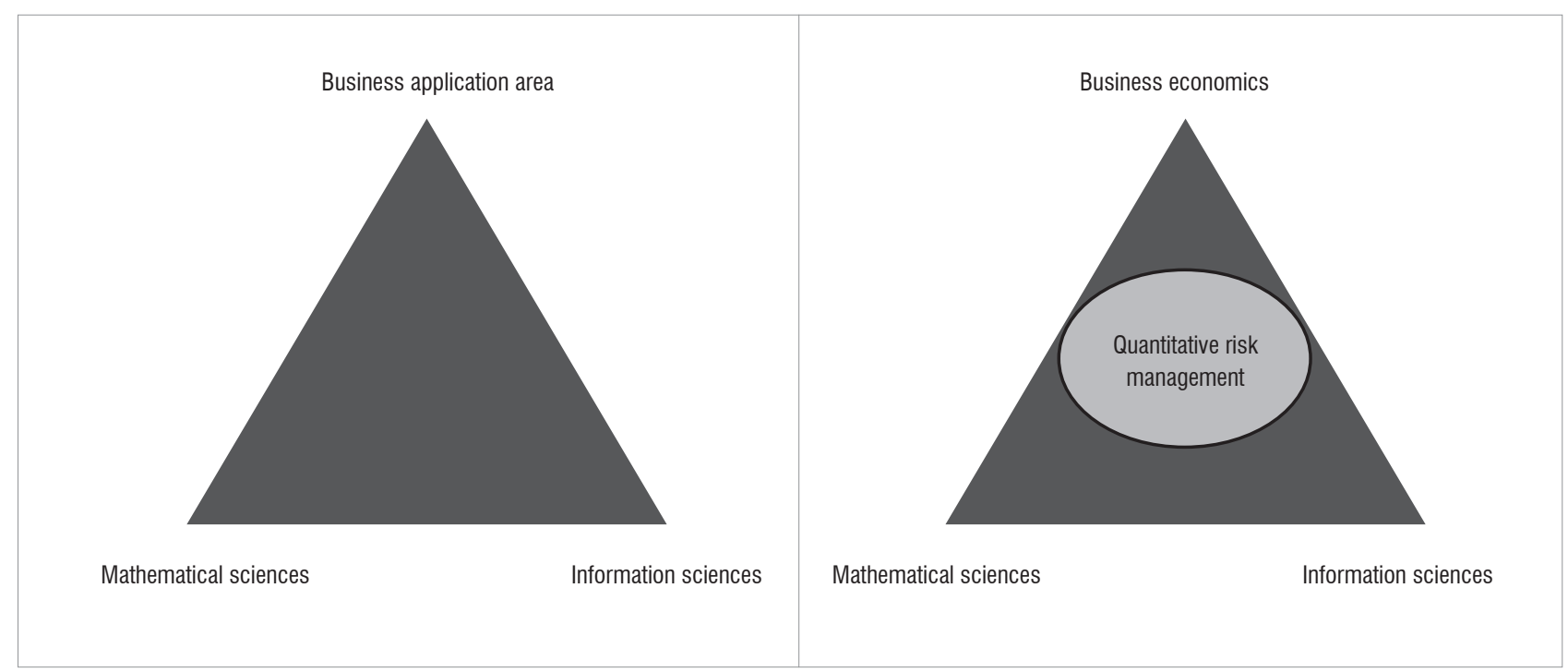

Figure 1: (a) The BMI Triangle and (b) our focused BMI Triangle. 


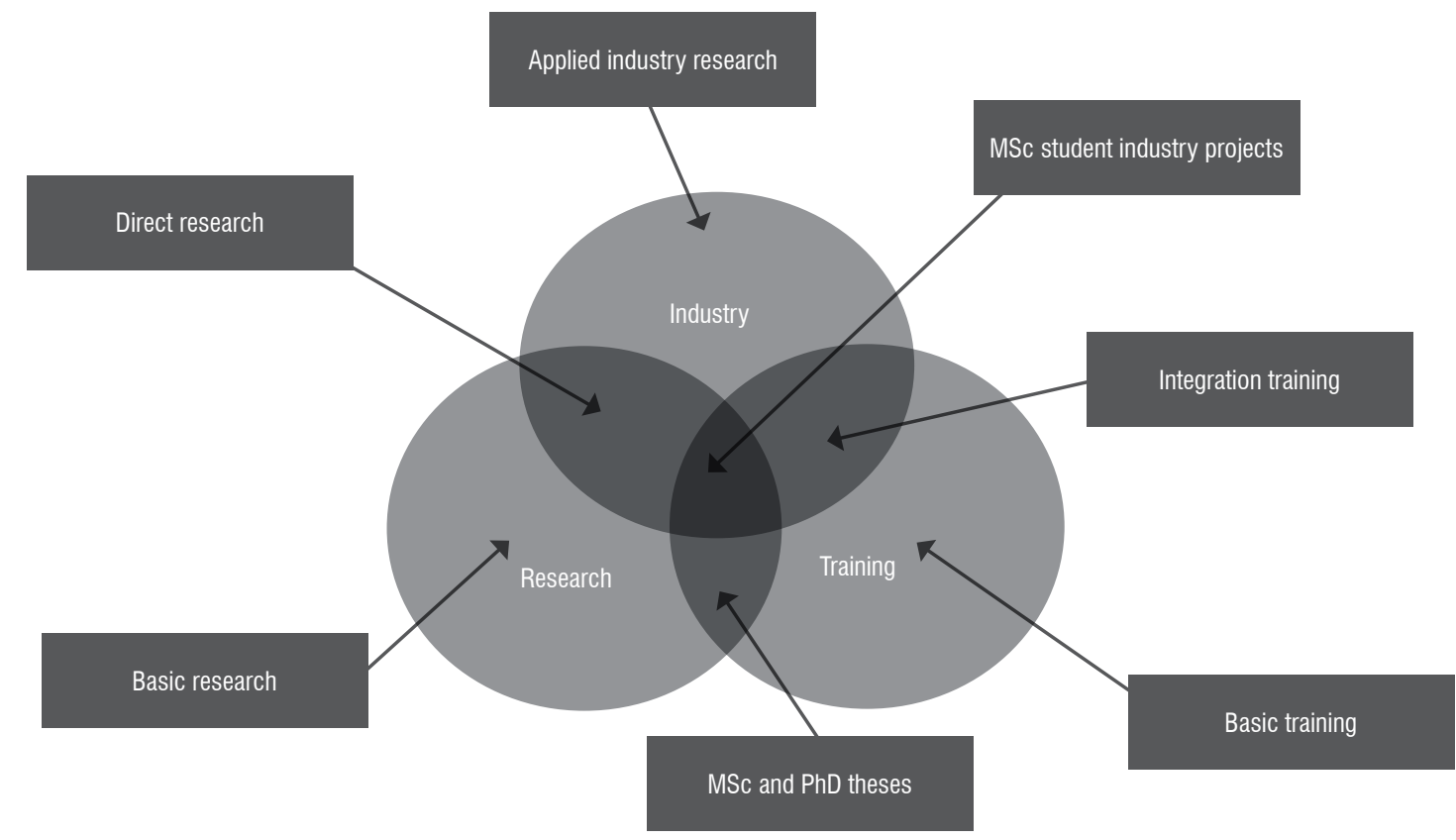

Figure 2: The design concept for implementation of the framework.

projects, should work on-site on the project to ensure that a first-hand knowledge of industry is obtained, and at least five formally organised meetings are required at the physical place of work to ensure that the academic supervisor experiences the business environment and interacts with the client organisation.

This process serves as a natural way of marketing the training and research programmes, as students have better job opportunities and supervisors have the opportunity to market their skills. This approach presents opportunities for the university to earn income from nongovernmental sources and for supervisors to direct their research towards the needs of industry. Also, from a marketing perspective, industry is exposed to the academic environment and the skills that exist there. Consequently, the gap between business and industry and the academic environment is naturally narrowed. Although the student industry-directed research projects essentially form part of a training activity, they also form part of research, which provides the link between industry and the university research programme.

The activities indicated as 'Basic Research' in Figure 2 are those involving traditional research activities by staff in the basic mathematical sciences, e.g. research on the improvement of statistical methodology such as the bootstrap. This type of research is usually of a 'technology push' nature, in the sense that research is usually based on the work of peers as observed in the open literature.

The activities labelled as 'Directed Research' are those activities carried out by staff in the chosen application area. Here researchers apply their research skills in the basic mathematical sciences to solve problems or develop methodologies in the chosen application area. Although the research is directed to the application area, it is also primarily of a technology push nature and predominantly based on the work of peers in the application area. The directed research programme was recently extended to include transdisciplinary research activities which entail directed research projects between industry and academia, but which are longer term in nature.

Unlike the projects undertaken under 'Directed Research', the activities in 'Applied Industry Research' are of a 'market pull' nature and are directly related to the needs of industry. Here staff tackle a specific problem posed by industry in order to generate income for the university, usually measured against short- to medium-term milestones. It should be noted that these activities have to be managed carefully against the specified milestones and should be conducted from an applied research perspective and do not take the form of pure consulting work per se. The nature of the work carried out is more medium term in nature rather than the very short-term milestones typically faced by consulting companies. As soon as the 'Applied Industry Research' projects are completed, a special effort is needed to generate transdisciplinary research papers co-authored by academics and clients as part of the 'Directed Research'. Figure 3 provides an illustration of the types of research activities in the knowledge-production chain - the long-term success of the research part of the framework is critically dependent on the alignment of the 'push' and 'pull' part of the chain, which requires active management from the research director.

The remaining training activities, depicted as MSc and PhD theses in Figure 2, are all the traditional training and research activities that result in theses written by students who study the basic mathematical sciences.

\section{Management and governance issues}

At this stage it should be clear that the activities carried out in the various areas of the implementation framework are quite diverse and that different people with different skill sets are involved in these activities. For example, the researcher operating on activities classified as 'Applied Industry Research' should have significant experience in solving business problems in the particular application area or should work under someone who has the relevant experience. Similarly, the researcher operating on 'Basic Research' activities should have experience in researching methodology in the basic mathematical sciences. The framework could also serve as a tool for the career planning of staff, because one could plot the progress of someone wishing to develop from 'Basic Research' to 'Applied Industry Research' or vice versa.

The diverse nature of the above-mentioned activities require that the university should seek to employ people well equipped for the particular task at hand, in particular to manage the interfaces between the different areas in the framework, as well as the framework as a whole. This in turn dictates different compensation and promotion strategies for the staff involved. 


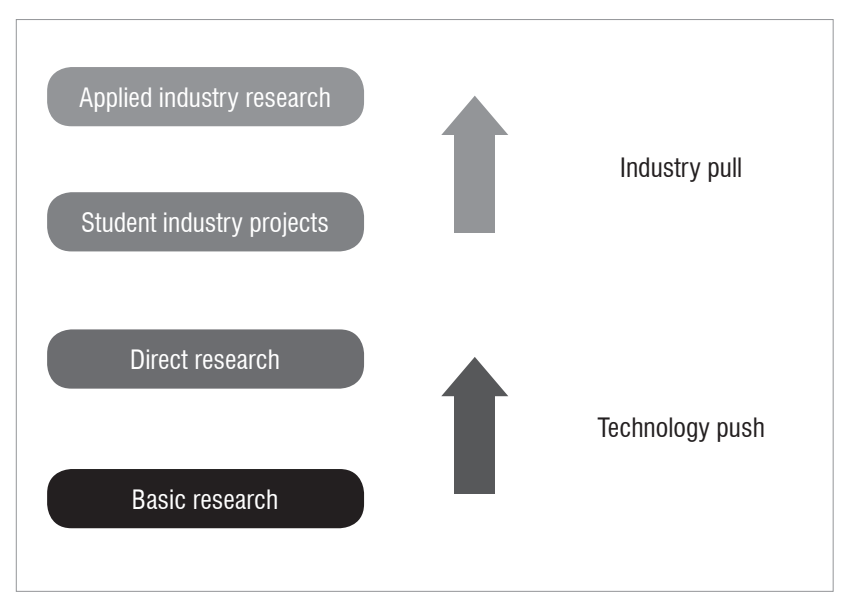

Figure 3: The knowledge-production chain.

The establishment of the capacity to conduct activities such as Directed Research and Applied Industry Research will most likely require some time before it reaches fruition. It is our recommendation that one should start by involving academics in the student industry projects in a supervisory capacity. By becoming involved in these projects, they will quickly grasp the problems faced by industry and identify the nature of the research required. At the same time, academics could acquaint themselves with the literature relevant to the emerging field and initiate directed research in the new application area.

Some academics may initially exhibit resistance to a change in their focus for obvious reasons, such as the time it will take to come to grips with the new research area. Management will have to adapt performance appraisal systems and promotion criteria so that industry-directed research is rewarded appropriately. Another issue is that industrydirected research projects are mostly classified as confidential, because of data issues and the possibility of commercialisation. Therefore it is important that universities address intellectual property issues upfront in these projects.

Appropriate governance structures are required for each set of the activities mentioned in the Implementation Framework. Most of these structures already exist at most universities for the 'Training' and 'Research' activities, but not for the 'Industry' activities in which the management of the industry-university relationship is of critical importance (for example see Edmonson et al. ${ }^{17}$ ). The governance and management structures of the BMI programme will be discussed in the next section, but in this case, separate management structures were required for each of the four sets of 'Industry' activities. Note also that separate governance structures are needed for each set of the 'Training', 'Research' and 'Industry' activities. At our university, the Centre for BMI has the responsibility for managing the 'Industry' activities, including the overlapping ones; the School for Statistics, Mathematics, and Computer Science for the non-overlapping 'Training' activities; and the Research Unit for BMI for the non-overlapping 'Research' activities.

\section{The BMI programme}

In this section we use the BMI programme as a case study to illustrate the implementation of our framework. We focus on the implementation of the BMI programme as far as the 'Industry' activities are concerned and discuss 'Integration Training', 'Directed Research', 'Student Industry Projects' and 'Applied Industry Research' separately in terms of implementation experience and the management and governance structures implemented.

Early in 1998 we formulated the vision of the Centre for BMI as follows:

To be a recognised player in the South African industry and the international academic world, and to obtain, develop and disseminate financial risk management expertise in close collaboration with the industry and public sector.
We defined our focus area as 'Quantitative Financial Risk Management' (which has recently been extended to include Business Analytics/Data Science). Therefore, in the early years of the Centre for BMI, the drive was to become a Centre of Expertise in Financial Risk Management solutions. Much of what is reported here focuses on the development of career-oriented training programmes and industry-directed research programmes for this field, but it is important to note that the same principles may be followed for other fields such as Data Science.

\section{Integration training}

\section{Implementation experience}

In order to ensure the introduction of subject-matter expertise into the programme, we liaised with the NWU School of Economics to introduce economics and finance courses within which the concepts of finance, banking and risk management are covered. These subjects were later replaced by courses in financial risk management which the School of Economics presented as part of a qualitative risk management programme. In the postgraduate programmes, several specialised courses in quantitative financial risk management had to be developed. In the end we settled on a mixture of material originating from the syllabi of the Institute and Faculty of Actuaries, the Global Association of Risk Professionals (GARP), the Professional Risk Managers' International Association (PRMIA) and books on related topics. ${ }^{18-20}$ The BMI curricula may be viewed on our website (www.nwu.ac.za/bmi) and contain courses in Quantitative Risk Management, Business Analytics/ Data Science, Financial Mathematics and Actuarial Science. The latter programme was acquired in 2000 from the Department of Statistics, when departmental management chose not to be troubled with the administrative burden of managing the exemptions and accreditation requirements of the Institute/Faculty of Actuaries. This was an important strategic decision, which paid tremendous dividends in recent years when the actuarial profession decided in 2008 to expand their global syllabi to include enterprise-wide risk management as part of their Certified Enterprise Risk Actuary qualification. At this time, and because of the widespread perceived excellence achieved in risk management training and research, the Centre for BMI was approached by the Actuarial Association of South Africa (ASSA) with a request for assistance with this initiative. It is important to note that the BMI courses include many programming courses, in particular SAS, while courses are presented in $\mathrm{R}, \mathrm{C \#}$ and Java (only for the data-mining curriculum). (Note that we have found SAS skills to be a job-differentiating factor in that students with these skills have a definite advantage when applying for jobs.) Great care has been taken to incorporate industry-relevant software systems training into our curricula, in particular, risk-management systems such as Risk Watch by Algorithmics, Front Arena by SunGard, and the portfolio risk management system BARRA on campus.

Another challenge was to ensure integration of the student's knowledge, in particular, to teach them how to use their mathematical and computer programming skills to solve real-world problems. To this end, we introduced BMI integration courses at first-year, third-year, honours and master's levels. In the first-year course, students are taught the basics of financial mathematics and are then required to develop a so-called retirement calculator utilising either MS Excel, C\# or Visual Basic. This calculator can then be used to plan a fellow student's retirement. The problem statement is presented to the students in the first class to allow them to experience how the theoretical concepts that they are taught build up to the point at which they are able to solve the problem. They are also given the opportunity to systematically develop a software system which can be designed and tweaked in order to handle changes in inputs. At the end of the year, the students present their system and are then required to solve some of the problems posed in the exam. In this way they learn how to present and market their system. We have found that this course goes a long way in assisting the student to develop a problemsolving mindset. The courses introduced on the other levels are similar in terms of the integration of mathematical formulation and computer programming skills, but a different and more challenging problem in the focus area has to be solved. We also realised that students at master's 
level had to be properly prepared for their industry-directed research project, and introduced a 32-credit integration-training module.

\section{Management structures}

A special effort had to be made to make the BMI programmes accessible to students from a previously disadvantaged background. In 2003, because of the language policies at the NWU's Potchefstroom Campus, we negotiated with the Dean of the School of Modelling Sciences at the Vaal Triangle Campus to present the undergraduate BMI training programme in English and changed the presentation language of all postgraduate BMI programmes to English. Absa's BMI bursary programme contributes annually to students following this programme. Absa manages the bursary programme in collaboration with the Centre for BMI and the progress of bursary holders is monitored closely through a Bursary Committee which has been established via a formal agreement. Each year, three formal meetings are scheduled at which representatives from Absa and BMI manage, inter alia, student progress, the allocation of new bursaries, employment within Absa, and repayment of bursaries by defaulters.

\section{Directed research}

\section{Implementation experience}

In order to properly focus research in the new field of quantitative financial risk management or risk analytics, we distinguish between basic-directed and transdisciplinary-directed research. Basic-directed research is defined as systematic study directed toward a more comprehensive knowledge or understanding of the fundamental aspects of risk management and analytics. This type of research is typically generated by researchers and depends largely on their personal interests and skills. This type of directed research is similar to basic research, with the difference being that the research is directed towards the particular field of interest, in this case risk management as opposed to, say, basic research in statistics or mathematics. On the other hand, the aim of transdisciplinary-directed research is to explore a theoretical or experimental research problem in order to achieve a defined industry goal in collaboration with industry.

In order to stimulate research in the new field of financial risk management, we decided to appoint a top-rated retired researcher in 2001. This appointment was made with the objective of gaining momentum for the basic-directed research programme. At present, the Centre for BMI contracts five retired researchers almost exclusively to do basic research in risk analytics and to supervise PhD students. As part of a recent memorandum of understanding signed between the Department of Science and Technology (DST) and Absa, the directed research programme received funds that are primarily used for transdisciplinarydirected research, but also for basic-directed research. At first, most of the funding was earmarked for basic-directed research projects which focused on the fundamental theory and aspects underlying (financial) risk analytics. As the programme matures, the emphasis is shifting to transdisciplinary-directed research projects with specific goals. The goals of these projects will typically be defined by industry (Absa and other financial services companies), the Reserve Bank and the NWU's Centre for BMI. During the first two years of running this virtual research programme, we managed to involve researchers from the University of Johannesburg, University of KwaZulu-Natal, University of Pretoria, University of South Africa and Stellenbosch University. Apart from Absa, where we held a workshop to formulate some transdisciplinary-directed research themes, we have attracted the interest of the Reserve Bank, National Treasury and Standard Bank with respect to our transdisciplinary research projects.

\section{Management structures}

Although formal project management procedures had to be implemented to manage the 'Applied Industry Research' projects, these procedures were used as guidelines and project management principles guided us in managing the directed research projects. Here we implemented the principle of goal-focused research for which we rewarded researchers who focused their research on the goals of the directed research programme, in line with predefined criteria and goals. The criteria were derived in collaboration with Absa and the DST and have been selected to support the Absa Applied Risk Research Programme.

The funds available for allocation among research projects is determined by an Assessment Committee comprising representatives from Absa, the DST and the Centre for BMI. Informal management structures exist for the selection and allocation of PhD applicants to supervisors, which are organised in an ad-hoc manner with the supervisor and student.

\section{Student Industry Projects}

\section{Implementation experience}

During the second semester of their master's degree, students are placed at a specific company for 3 or 4 days per week, where they are required to apply their knowledge and skills in solving a real industry problem with the requirement that value is added to the company. This process is well structured and managed according to a specific methodology and is very popular in the financial services industry. We have documented the methodology as part of a procedure guide ${ }^{16}$ which contains details on the project management process, documentation packs, minutes of project meetings, responsibilities of the Project Steering Committee members, preparation for meetings, report templates and structure, project close out procedures and assessment details.

As mentioned previously, a module has been introduced in the first semester of the MSc in order to prepare the student for the second semester industry-directed research project. This module contains lectures on creative problem solving, project management, meeting administration, report writing and business communication. Typically, two students are assigned to a project, which is concerned with solving a problem for a local client (e.g. from within the university, local industry, municipality or the defence force). These problems are typically of a management consulting nature and usually involve developing a decision support system, which is typically computer based. The problems are specifically chosen to fall outside the risk management field to force the student to think 'out of the box' and to learn to apply the project management processes and principles properly. As instructors we follow a hard and provocative line during the Project Steering Committee meetings at which students are required to answer the typical why, what, where and how questions. The objectives are to drill students in question answering and persuasion techniques and in thinking 'on their feet' when answering questions, in order to prepare them to deal with any personality type they may encounter when they do their industry projects in the second semester.

Overall, this process has several benefits: students find work easily and the feedback from industry allows us to ensure that the training and research programmes remain highly relevant to industry. This process also has several advantages for industry partners, such as:

- An opportunity to complete those projects that never seem to make it to the top of the priority list.

- Access to the skills of a nearly qualified student, with the backing of an academic mentor, at a very low cost.

- An opportunity for a 6-month on-the-job evaluation of a prospective employee, before deciding to offer them a job. (This option is far more cost effective than working through a placement agency.)

\section{Management structures}

Each student project is managed by a Project Steering Committee, which comprises a client project sponsor, client project manager, client project officer, director of the Centre for BMl, academic project supervisor and the student. A detailed list of the responsibilities of each person is provided in the procedure guide..$^{16}$ In short, the client project officer and academic project supervisor are required to meet with the student and discuss project progress on a weekly basis. These meetings usually take 
place on Mondays (with the client project officer at the client company) and on Fridays (with the academic project supervisor at the university). The client project officer is responsible for managing the business relevance to the company, while the academic project supervisor is responsible for monitoring the academic/technical quality. Regular meetings require the student to keep informal minutes and are necessary to keep the project on track. Four formal Steering Committee meetings referred to as the Business Case, Project Proposal, Progress Review and Project Close-out - take place at the premises of the client and require formal documentation packs and minutes of meetings. The evaluation of the final report follows a rigorous process which is very similar to the formal theses assessment process, with the exception that slightly modified evaluation criteria are used. One aspect of the extra criteria included is the consideration of the value and benefits provided by the project to business. To date, about $90 \%$ of the student projects delivered have received a high to very high rating. (Based on our experience in the consulting environment, this rate is much higher than the success rate experienced by consulting companies.)

\section{Applied Industry Research}

\section{Implementation experience}

In the years prior to the commencement of this programme in 2006 it became clear that a business value-adding activity was required to motivate the continued contractual relationship between Absa and the Centre for BMI. Although Absa had acknowledged the substantial benefit of the students and the industry-directed research projects delivered, they had provided bursaries to the students and by then had invested a large amount of capital for the capacity-building phase. The BMI training programme was well established, but other companies in the financial services were also benefitting from the programme - in fact, only $35 \%$ of the BMI MSc graduates are employed by Absa. As a result, it became clear that an additional service had to be introduced to ensure renewal of the contract. During 2005, an important strategic initiative was launched to involve staff in Absa applied research projects, subsequent to which Absa decided to renew their contract in 2006, this time with the inclusion of an umbrella contract for Applied Industry Research projects. Today the value of this contract is just over ZAR1.5 million and a number of research reports have been delivered - an average of 13 projects are completed each year. Most of the projects were done for clients in Absa middle management, which, together with the student projects, ensured that BMI staff obtained high visibility in Absa. Other institutions also came to know about the BMI capabilities, and today a number of companies are interested in using the Centre for BMI as independent evaluators or validators of their models.

\section{Management structures}

Although the management of the programme started off in an ad-hoc way, the processes have now been formalised. A project management procedure, similar to that employed during the course of the student projects, has been instituted in an augmented form to ensure a proper audit and reporting trail for the completion of projects in terms of the initial client requirement as well as to ensure business value. An Absa Risk Research Steering Committee manages the process with the responsibility to ensure good governance in terms of value and funding and to make sure that follow-up work is done. Each year a report is issued which contains the value-added ratings by the clients of the various projects performed in the previous year. Although BMI staff salaries were augmented by Absa funds, it was difficult at first to motivate BMI personnel to become involved in the Absa projects, mainly because of the profit sharing policy of the university, which rewarded personnel who worked on projects conducted on a one-to-one basis and not those under an umbrella contract. As soon as the profit sharing policy was adjusted to also incorporate the Absa umbrella project, personnel became motivated to take part in the Absa projects.

As stated earlier, the Centre for BMI is involved in two long-term contracts with industry partners Absa and SAS. Both contracts are managed by Steering Committees consisting of representatives from
Absa, SAS and NWU. An Advisory Board manages the Absa interface with executive representation from Absa Human Resources, Absa Financial Services, Absa Group Risk, SAS, the DST and NWU. The Advisory Board meets once a year and provides strategic level direction and oversight to the activities of the Centre for BMI. Recently, the Board tasked us with designing a framework for measuring the success of the relationships between the NWU and Absa. In order to do this, we adapted the industry-university evaluation framework suggested by Perkman et al. ${ }^{21}$ for our purposes.

\section{Concluding remarks and lessons learnt}

In the process of designing the BMI programme, several important lessons were learnt. Some of the most important ones are:

- The people responsible for managing the university-industry interface should be good managers who understand the process of problem solving, should have industry experience in applying the mathematical sciences to solve business problems and should understand research and the associated difficulties. Managing this interface with industry is a full-time job, and cannot be expected from an academic on an over-and-above basis.

- It is important to focus on a particular area of application. We initially worked from the generic BMI base, trying to 'be all things to all people'. You cannot have meaningful discussion with industry without a specific focus in a chosen application area. (In the end it turned out that our chosen focus, quantitative risk management, was anyway a massive field.)

- Without active support from senior (top) management within the university and the industry sponsor(s), the effort is a non-starter. On the other hand, university management who have no industry experience and are 'traditional academics' may find it difficult to cope with the demands, frustrations and speedy decisions that are required when managing the 'Industry' activities.

- Effective integration and co-operation across faculty and/or departmental boundaries is crucial - establishing a team spirit with a common vision and breaking down the traditional academic silos are essential.

- The Student Industry Projects, although they require extensive management and academic time investment, represent a critical success factor for the initiative, as it forces the two parties to engage with one another and move out of their comfort zones. Furthermore, they create frequent communication opportunities and act as a natural marketing activity.

- Active partnering with credible professional bodies (e.g. GARP, PRMIA, ASSA) and with relevant software companies (e.g. SAS, Sungard, Barra) lends further credibility to the initiative.

- It is important to note that the BMI programme focuses on the delivery of professionally trained students to industry and not on training academics; therefore, students who have completed a BMI MSc and wish to register for a PhD in the mathematical sciences (e.g. mathematics or statistics) will require additional advanced discipline-specific training.

In this paper, we proposed a framework that can be used to design and implement career-oriented training programmes with a statistical science core. The essential elements of the framework are that it is:

- Multidisciplinary - in our case, it consists of a sound undergraduate base in statistics, mathematics, computer science, banking and financial economics.

- Structured around a specific focus in the application area - in our case, quantitative financial risk management, recently expanded to data science.

- Career-orientated, with the curriculum reverse-engineered from the identified careers - in our case, financial risk manager, investment 
manager, financial engineer, financial statistician/mathematician and data-miner.

- Practical, as facilitated by the specific selection of staff with the skills and experience to operate 'inside' the triangle in Figure 1, and involves active practitioners from industry in the training programme.

- Integrated, in the sense that there are specific courses incorporated in the curriculum - in our case, on first-, third- and fifth-year levels - to actively integrate the knowledge between the corners of the triangle, together with the non-technical skills discussed earlier.

- Backed by a well-structured research unit, with clearly defined goals and management responsibilities, and an applied research programme in financial risk analysis, which is aligned with the declared focus in financial risk management.

This framework has been used to successfully design and implement the BMI programme at the NWU. We believe that the mathematical sciences departments at any university should be able to use this framework to design and implement career-oriented training programmes. The key, however, is to choose the right application area and right champions, to find an interested and committed business partner, and to gain acceptance, approval and support from university authorities. Also, we should take care to not focus on the same area, but to rather collaborate, and share ideas to the benefit of all.

\section{Acknowledgements}

We have spent half of our professional lives implementing the careeroriented and industry-directed research programmes at the Centre for BMI. Although we played the leading role in all of the strategic initiatives, various people in Absa, the NWU and SAS - too numerous to list contributed significantly to the success of the BMI programme. We also thank the editor, as well as BMI alumna Elzabe Marais, for comments that improved the presentation of the paper.

\section{Authors' contributions}

Both authors contributed equally to the manuscript.

\section{References}

1. Boersma FK, Reinecke CJ, Gibbons M. Organizing the university-industry relationship: A case study of research policy and curricullum restructuring at the North-West University in South Africa. Tertiary Educ Manage. 2008;14(3):209-226. http://dx.doi.org/10.1080/13583880802228216

2. Hand DJ. Data mining: Statistics and more? Amer Statist. 1998;52:112-118.

3. Lambert D. Discussion of 'Key challenges for statisticians in business and industry' by Hahn and Hoerl. Technometrics. 1998;40:201-202. http:// dx.doi.org/10.1080/00401706.1998.10485517
4. Nelder JA. Statistics for the millenium: From statistics to statistical science. Statistician. 1999;48(2):257-269. http://dx.doi.org/10.1111/14679884.00187

5. Lawless JF. Statistical science: Concepts, opportunities and challenges. Canad J Statist. 1999;27:671-682. http://dx.doi.org/10.2307/3316124

6. Hahn GH, Hoerl RW. Key challenges for statisticians in business and industry. Technometrics. 1998;40:195-213. http://dx.doi.org/10.1080/00401706.19 98.10485516

7. Billard L. The role of statistics and the statistician. Amer Statist. 1998;52:319324.

8. Snee RD. Discussion of 'Key challenges for statisticians in business and industry' by Hahn and Hoerl. Technometrics. 1998;40:207-210. http:// dx.doi.org/10.1080/00401706.1998.10485520

9. Kettenring JR. Shaping statistics for success in the 21st century. J Amer Statist Assoc. 1997;92:1229-1234. http://dx.doi.org/10.1080/01621459.1 997.10473641

10. McDonald GC. Shaping statistics for success in the 21 st century: The needs of industry. Amer Statist. 1999;53:203-207.

11. Meyer RD, Trost DC, Vukovinsky KE. Discusssion of 'Key challenges for statisticians in business and industry' by Hahn and Hoerl. Technometrics. 1998;40:203-205.

12. Gnanadesikan R, Kettenring JR. Statistics teachers need experience with data. College Math J. 1988;19:12-14. http://dx.doi.org/10.2307/2686689

13. Iman RL. Statistics departments under siege. Amstat News. 1994;244:8.

14. Geller NL. Statistics: An all-encompassing discipline. J Amer Statist Assoc. 2011;106(496):1225-1229. http://dx.doi.org/10.1198/jasa.2011.ap11592

15. Rodriguez RN. Building the big tent for statistics. J Amer Statist Assoc. 2013;108(501):1-6. http://dx.doi.org/10.1080/01621459.2013.771010

16. Erasmus CM, De Jongh PJ. Procedure for conducting BMI industry directed research projects: Study guide for BWIN826. Potchefstroom: Centre for BMI, North-West University; 2012.

17. Edmonson G, Valigar L, Kenward M, Hudson RL, Beield H. Industry-university partnerships work: Lessons form successful collaborations. Report commissioned by the Science Business Innovation Board; 2012.

18. McNeil AJ, Frey R, Embrechts P. Quantitative risk management: Concept, technique and tools: Oxford: Princeton University Press; 2005.

19. Jorion P. Financial risk manager handbook plus test bank. 6th ed. Hoboken, NJ: Wiley; 2011.

20. Sweeting P. Financial enterprise risk management. Cambridge: Cambridge University Press; 2011. http://dx.doi.org/10.1017/CB09780511844133

21. Perkman M, Neely A, Walsh K. How should firms evaluate success in industryuniversity alliances? A performance measurement system. R\&D Manage. 2011;41(2):202-216. http://dx.doi.org/10.1111/j.1467-9310.2011.00637.x 